\title{
Acute effects of renal sympathetic denervation guided by renal nerve stimulation in CKD patients with ICD
}

\author{
Márcio Galindo Kiuchi ${ }^{*}$, and Shaojie Chen ${ }^{2}$ \\ ${ }^{1}$ Division of Cardiac Surgery and Artificial Cardiac Stimulation, Department of Medicine, Hospital e Clínica São Gonçalo, São Gonçalo, RJ, Brazil \\ ${ }^{2}$ Department of Cardiology, Shanghai First People's Hospital, Shanghai Jiao Tong University School of Medicine, Shanghai, China
}

In the United States, statistics indicate that there are approximately one million annual deaths from cardiovascular disease, of which 330,000 are the result of sudden death [1,2]. It is well established in the literature the relationship between structural heart disease and the occurrence of SCD. In over $70 \%$ of cases, the underlying heart disease is the myocardial ischemia [3]. The importance of automatic implantable cardioverter-defibrillator (ICD) has been demonstrated in patients with previous myocardial infarction and severe systolic left ventricular dysfunction (secondary prevention) [4,5]. Survivors of cardiac arrest or those with sustained ventricular tachycardia at high risk of recurrence of such events [6]. The therapies used include antiarrhythmic drugs, surgical resection, endocardial catheter ablation and use of the implantable electronic cardiac device.

Sympathetic overactivity is well known to rise cardiovascular risk in patients with chronic kidney disease (CKD) [7-9]. In CKD, sympathetic overactivity seems to manifest at the earliest stage of clinical disease, showing a straight relationship with the severity of the illness of renal failure [10-13]. As the decrease in the glomerular filtration rate occurs, there is also an increase in cardiovascular events and mortality in patients with CKD [14], especially due to arrhythmic events and their consequences. We previously reported that in the presence of ventricular tachycardia, the anti-tachycardia pacing therapy (ATP) or synchronized cardioversion shock, and in cases of ventricular fibrillation detection, the ICD applies an unsynchronized shock of high energy defibrillation. These events are more common in CKD patients on stage 4 [15].

This study examined patients who underwent ICD implantation in patients with CKD on stage 4. We aim to compare the acute effect of renal sympathetic denervation (RSD) guided by renal nerve stimulation (RNS). This transversal study was piloted at the Department of Cardiac Artificial Stimulation and Cardiac Surgery of the Hospital e Clínica São Gonçalo, São Gonçalo, Rio de Janeiro, Brazil. A cohort of patients received standard therapy for primary or secondary prevention of sudden cardiac death (SCD) in patients with structural heart disease, subjected to the ICD-DR implant according to the "Guidelines for Implantable Electronic Cardiac Devices of the Brazilian Society of Cardiology" [16]. Inclusion criteria were as follows: (i) subjects with structural heart disease and ICD implantation indication for primary or secondary prevention of SCD; (ii) left ventricular ejection fraction $\leq 35 \%$; (iii) patients who provided documentation not presenting cardiac ischemia before ICD implantation evidenced by myocardial scintigraphy at rest and during stress or coronary angiography; (iv) estimated glomerular filtration rate (eGFR) by the CKD-EPI (Chronic Kidney Disease Epidemiology Collaboration) equation, eGFR [17] between 15 and $29 \mathrm{~mL} / \mathrm{min} / 1.73 \mathrm{~m}^{2}$. Exclusion criteria were: (i) ischemic heart disease; (ii) $\mathrm{LVEF}>35 \%$; (iii) absence of structural heart disease; (iv) valvar heart disease that might lead to arrhythmias; (v) the presence of previously documented atrial fibrillation. The recruitment of the patients began in January 2012 and ended in June 2015. We enrolled 40 patients with CKD on stage 4 identified in our offices. The study was conducted in agreement with the Declaration of Helsinki and was approved by the Ethics Committee of our hospital. All individuals provided written informed consent before inclusion in the study.

The 40 subjects with $\mathrm{CKD}$ on stage 4 were randomly divided into two groups (RNS, $n=20$, and RNS+RSD, $n=20$ ). The subjects underwent RSD were submitted to an acute subsequently RNS. The implantation and programming of the ICDs, twenty-four hour ABPM, and transthoracic echocardiography were previously reported in detail in our previously manuscript [15]. The 80 (40 leftt and 40 right) renal arteries from the $40 \mathrm{CKD}$ patients on stage 4 were stimulated according to 16 pattern quadrant previously described by our group [18]. After the stimulation, we waited for the BP to return to baseline values and when ventricular tachycardia (VT) event occurred together we also waited for the rhythm return to the sinus rhythm, what happened spontaneously after stopping the RNS, and before proceeding to the next stimulation site. The patients remained hospitalized in the ward for $24 \mathrm{~h}$ after the procedure. Twenty CKD patients on stage 4 underwent RSD guided by RNS and submitted to to an acute subsequently RNS. The RSD was previously described in detail by our group [19].

All patients enrolled were included in the analysis. The results were expressed as the mean and standard deviation (mean \pm SD) in the case of normal distribution and as median with interquartile range otherwise. Statistical tests were all of two sides. Comparisons between the two paired values were performed by paired t-test in case of Gaussian distribution or alternatively, by Wilcoxon test. The comparisons between more than two values paired values were performed by analysis of variance for repeated measures ANOVA or Kruskal-Wallis test, as appropriate, complemented by a post hoc test. Frequencies were compared with $x^{2}$ or Fisher's exact tests. P values $<0.05$ were considered significant. Correlations between two variables were performed by Pearson in the case of Gaussian distribution or,

Correspondence to: Márcio Galindo Kiuchi, Division of Cardiac Surgery and Artificial Cardiac Stimulation, Department of Medicine, Hospital e Clínica São Gonçalo, Rua Cel. Moreira César, 138 - Centro, São Gonçalo, Rio de Janeiro 24440-400, Brazil, Tel/Fax: +55 (21) 26047744, E-mail: marciokiuchi@gmail.com

Received: January 04, 2017; Accepted: January 19, 2017; Published: January 23, 2017 
alternatively, with the Spearman correlation test. All statistical analyzes were performed using the program Graphpad Prism v 7.0 (Graphpad software, La Jolla, CA, USA).

The 40 patients who presented the inclusion criteria were included in the study. The baseline characteristics, like age, body mass index, gender, ethnicity and other features of the patients in the both groups are disposed of in detail in Table 1.

The correlation between the variation $(\Delta)$ in invasive systolic BP and VT occurrence in each quadrant of the left and right renal arteries by Pearson method during the RNS for CKD patients on stage 4 which

Table 1. Baseline features.

\begin{tabular}{|c|c|c|c|}
\hline & $\begin{array}{c}\text { CKD stage } 4 \\
\text { RNS }\end{array}$ & $\begin{array}{c}\text { CKD stage } 4 \\
\text { RNS+RSD }\end{array}$ & Overall P value \\
\hline $\mathrm{N}$ & 20 & 20 & --- \\
\hline Age, years & $64.0 \pm 15.5$ & $70.0 \pm 13.0$ & 0.1899 \\
\hline Body mass index, $\mathrm{kg} / \mathrm{m}^{2}$ & $27.3 \pm 6.3$ & $26.8 \pm 6.8$ & 0.8107 \\
\hline Male gender $(\%)$ & $16(80 \%)$ & $13(65 \%)$ & 0.4801 \\
\hline White ethnicity (\%) & $15(75 \%)$ & $16(80 \%)$ & $>0.9999$ \\
\hline Type 2 Diabetes Mellitus (\%) & $10(50 \%)$ & $12(60 \%)$ & 0.7512 \\
\hline Coronary artery disease & $16(80 \%)$ & $17(85 \%)$ & $>0.9999$ \\
\hline Ischemic etiology & $16(80 \%)$ & $17(85 \%)$ & $>0.9999$ \\
\hline Mean 24-hour ABPM, mmHg & $123 \pm 7 / 75 \pm 4$ & $122 \pm 8 / 76 \pm 2$ & $0.6763 / 0.3236$ \\
\hline Creatinine, $\mathrm{mg} / \mathrm{dL}$ & $2.62 \pm 0.08$ & $2.61 \pm 0.10$ & 0.7289 \\
\hline $\mathrm{eGFR}, \mathrm{mL} / \mathrm{min} / 1.73 \mathrm{~m}^{2}$ & $25.0 \pm 3.2$ & $24.0 \pm 2.6$ & 0.2849 \\
\hline $\mathrm{ACR}, \mathrm{mg} / \mathrm{g}$ & $74.8 \pm 15.0$ & $77.9 \pm 12.7$ & 0.4849 \\
\hline \multicolumn{4}{|l|}{ Antiarrhythmic agent } \\
\hline Amiodarone & $20(100 \%)$ & $20(100 \%)$ & 1.0000 \\
\hline \multicolumn{4}{|l|}{ Antihypertensive agents } \\
\hline ACEI/ARB & $20(100 \%)$ & $20(100 \%)$ & 1.0000 \\
\hline Spironolactone & $20(100 \%)$ & $20(100 \%)$ & 1.0000 \\
\hline DHP Ca ${ }^{++}$channel blockers & $10(50 \%)$ & $11(55 \%)$ & $>0.9999$ \\
\hline$\beta$-blockers & $20(100 \%)$ & $20(100 \%)$ & 1.0000 \\
\hline \multicolumn{4}{|l|}{ Echocardiographic parameters } \\
\hline LVMI, $\mathrm{g} / \mathrm{m}^{2}$ & $155.7 \pm 11.1$ & $153.4 \pm 7.8$ & 0.4530 \\
\hline LVEF, \% & $28.4 \pm 6.0$ & $27.8 \pm 5.3$ & 0.7393 \\
\hline LVIDED, mm & $68.3 \pm 14.5$ & $67.3 \pm 11.4$ & 0.8097 \\
\hline LVIDES, mm & $54.0 \pm 18.0$ & $53.5 \pm 15.6$ & 0.9257 \\
\hline
\end{tabular}

The values are presented as mean $\pm \mathrm{SD}$ or $\%$; ABPM: ambulatory blood pressure monitoring; ACEI: receptor inhibitor of angiotensin converting enzyme; ACR: albumin:creatinine ratio; ARB, angiotensin receptor blocker; CKD: chronic kidney disease; DHP: dihydropyridyne; eGFR: estimated glomerular filtration rate; LVMI: left ventricular mass index; LVEF: left ventricular ejection fraction measured by Simpson's method; LVIDED: left ventricle internal dimension at the end of diastole; LVIDES: left ventricle internal dimension at the end of systole; $\mathrm{N}$ : number of patients; RSD: renal sympathetic denervation; RNS: renal nerve stimulation.

Table 2. Sites where VT occurred during RNS, n (\%) in CKD patients on stage 4 ( $\mathrm{n}=40$ patients).

\begin{tabular}{|c|c|c|c|c|c|c|}
\hline \multirow{3}{*}{\begin{tabular}{|l|}
\multicolumn{1}{|c|}{ Sites } \\
RNS per quadrant $(\mathrm{n}=$ sites $)$ \\
\end{tabular}} & \multirow{2}{*}{\multicolumn{2}{|c|}{$\begin{array}{l}20 \text { patients }=40 \text { renal arteries } \\
\text { RNS in the RNS group only }\end{array}$}} & \multicolumn{4}{|c|}{20 patients $=40$ renal arteries } \\
\hline & & & \multicolumn{2}{|c|}{ RNS before RSD in the RNS+RSD group } & \multicolumn{2}{|c|}{$\begin{array}{l}\text { RNS after RSD in the RNS+RSD group, only in } \\
\text { the sites where VT occurred }\end{array}$} \\
\hline & 20 LRA $(n=320)$ & 20 RRA $(n=320)$ & 20 LRA $(n=320)$ & 20 RRA $(n=320)$ & 20 LRA $(n=200)$ & 20 RRA $(\mathrm{n}=140)$ \\
\hline Quadrant1 - Ostium & $14(70 \%)$ & $13(65 \%)$ & $12(60 \%)$ & $18(90 \%)$ & $1(5 \%)^{* * * *}$ & $3(15 \%)^{* * *}$ \\
\hline Quadrant2 - Ostium & $14(70 \%)$ & $9(45 \%)$ & $14(70 \%)$ & $18(90 \%)$ & $2(10 \%)^{* * * *}$ & $3(15 \%)^{* * *}$ \\
\hline Quadrant3 - Ostium & $11(55 \%)$ & $9(45 \%)$ & $15(75 \%)$ & $19(95 \%)$ & $4(20 \%)^{*}$ & $3(15 \%)^{* * *} *$ \\
\hline Quadrant4 - Ostium & $15(75 \%)$ & $0(0 \%)$ & $17(85 \%)$ & $0(0 \%)$ & $6(30 \%)^{* * *}$ & --- \\
\hline Quadrant1 - Proximal & $17(85 \%)$ & $10(50 \%)$ & $20(100 \%)$ & $0(0 \%)$ & $1(5 \%)^{* * * *}$ & --- \\
\hline Quadrant2 - Proximal & $12(60 \%)$ & $12(60 \%)$ & $0(0 \%)$ & $20(100 \%)$ & --- & $4(20 \%)^{* * *}$ \\
\hline Quadrant3 - Proximal & $0(0 \%)$ & $0(0 \%)$ & $0(0 \%)$ & $0(0 \%)$ & --- & --- \\
\hline Quadrant4 - Proximal & $0(0 \%)$ & $0(0 \%)$ & $0(0 \%)$ & $0(0 \%)$ & --- & --- \\
\hline Quadrant1 - Middle & $0(0 \%)$ & $0(0 \%)$ & $0(0 \%)$ & $0(0 \%)$ & --- & --- \\
\hline Quadrant2 - Middle & $0(0 \%)$ & $0(0 \%)$ & $0(0 \%)$ & $0(0 \%)$ & --- & --- \\
\hline Quadrant3 - Middle & $15(75 \%)$ & $9(45 \%)$ & $20(100 \%)$ & $20(100 \%)$ & $4(20 \%)^{* * *}$ & $2(10 \%)^{* * * *}$ \\
\hline Quadrant4 - Middle & $0(0 \%)$ & $0(0 \%)$ & $0(0 \%)$ & $0(0 \%)$ & --- & --- \\
\hline Quadrant1 - Distal & $0(0 \%)$ & $12(60 \%)$ & $0(0 \%)$ & $15(75 \%)$ & --- & $4(20 \%)^{* * *}$ \\
\hline Quadrant2 - Distal & $0(0 \%)$ & $14(70 \%)$ & $20(100 \%)$ & $0(0 \%)$ & $4(20 \%)^{* * * *}$ & --- \\
\hline Quadrant3 - Distal & $14(70 \%)$ & $0(0 \%)$ & $14(70 \%)$ & $0(0 \%)$ & $6(30 \%)^{*}$ & --- \\
\hline Quadrant4 - Distal & $12(60 \% \%)$ & $0(0 \%)$ & $0(0 \%)$ & $16(80 \%)$ & --- & $4(20 \%)^{* * *}$ \\
\hline
\end{tabular}

CKD: chronic kidney disease; LRA: left renal artery; RNS: renal nerve stimulation; RRA: right renal artery; RSD: renal sympathetic denervation; VT: ventricular tachycardia; "P $<0.05$ ${ }^{* *} \mathrm{P}<0.001$, and ${ }^{* * *} \mathrm{P}<0.0001$ for comparisons between RNS after RSD in the RNS+RSD group vs. RNS in the RNS group only and RNS before RSD in the RNS+RSD group of renal arteries at the same side of the body. 
Table 3. $\Delta$ mean invasive systolic BP during RNS, mmHg in CKD patients on stage 4 ( $\mathrm{n}=40$ patients).

\begin{tabular}{|c|c|c|c|c|c|c|}
\hline \multirow{3}{*}{\begin{tabular}{|l|}
\multicolumn{1}{|c|}{ Sites } \\
RNS per quadrant $(\mathrm{n}=\mathrm{sites})$ \\
\end{tabular}} & \multirow{2}{*}{\multicolumn{2}{|c|}{$\begin{array}{c}20 \text { patients }=40 \text { renal arteries } \\
\text { RNS in the RNS group only }\end{array}$}} & \multicolumn{4}{|c|}{20 patients $=40$ renal arteries } \\
\hline & & & \multicolumn{2}{|c|}{ RNS before RSD in the RNS+RSD group } & \multicolumn{2}{|c|}{$\begin{array}{l}\text { RNS after RSD in the RNS+RSD group, only in } \\
\text { the sites where VT occurred }\end{array}$} \\
\hline & 20 LRA $(n=320)$ & $20 \operatorname{RRA}(\mathrm{n}=320)$ & 20 LRA $(n=320)$ & 20 RRA $(n=320)$ & 20 LRA $(\mathrm{n}=200)$ & 20 RRA $(n=140)$ \\
\hline Quadrant1 - Ostium & $27.6 \pm 4.3$ & $27.3 \pm 4.4$ & $26.3 \pm 3.7$ & $29.5 \pm 4.1$ & $16.4 \pm 4.4^{* * / * * *}$ & $19.4 \pm 5.3^{* * * * * *}$ \\
\hline Quadrant2 - Ostium & $28.4 \pm 5.4$ & $26.8 \pm 7.0$ & $27.4 \pm 4.3$ & $30.2 \pm 5.0$ & $17.1 \pm 5.1^{* * / * * *}$ & $19.9 \pm 4.8^{* / * *}$ \\
\hline Quadrant3 - Ostium & $26.3 \pm 5.7$ & $25.6 \pm 6.4$ & $28.4 \pm 6.6$ & $29.6 \pm 3.5$ & $18.1 \pm 7.0^{* / * * *}$ & $20.0 \pm 4.5^{* / * *}$ \\
\hline Quadrant4 - Ostium & $27.8 \pm 3.8$ & $6.8 \pm 7.0$ & $30.4 \pm 3.4$ & $6.5 \pm 4.7$ & $20.7 \pm 5.5^{* * / * * *}$ & --- \\
\hline Quadrant1 - Proximal & $27.8 \pm 3.3$ & $28.9 \pm 9.0$ & $29.7 \pm 2.7$ & $8.2 \pm 6.2$ & $19.1 \pm 3.0^{* * * * * *}$ & --- \\
\hline Quadrant2 - Proximal & $25.7 \pm 2.8$ & $28.8 \pm 7.3$ & $10.0 \pm 8.5$ & $31.5 \pm 5.2$ & --- & $21.1 \pm 6.0^{* / * * *}$ \\
\hline Quadrant3 - Proximal & $8.3 \pm 5.1$ & $6.0 \pm 5.7$ & $10.8 \pm 4.1$ & $4.3 \pm 5.4$ & -- & --- \\
\hline Quadrant4 - Proximal & $7.3 \pm 4.1$ & $6.9 \pm 5.5$ & $9.2 \pm 4.9$ & $7.7 \pm 7.3$ & --- & --- \\
\hline Quadrant1 - Middle & $5.8 \pm 5.0$ & $7.5 \pm 4.6$ & $8.7 \pm 5.1$ & $6.3 \pm 3.8$ & --- & --- \\
\hline Quadrant2 - Middle & $7.1 \pm 6.6$ & $5.8 \pm 5.2$ & $7.1 \pm 6.6$ & $4.8 \pm 4.8$ & --- & -- \\
\hline Quadrant3 - Middle & $28.2 \pm 4.8$ & $25.1 \pm 5.1$ & $30.4 \pm 3.9$ & $30.3 \pm 2.2$ & $21.9 \pm 3.8^{* * / * * *}$ & $20.6 \pm 3.4^{* / / * *}$ \\
\hline Quadrant4 - Middle & $4.2 \pm 4.3$ & $3.6 \pm 4.0$ & $3.0 \pm 3.5$ & $6.0 \pm 5.0$ & --- & --- \\
\hline Quadrant1 - Distal & $4.9 \pm 6.4$ & $30.3 \pm 8.1$ & $4.6 \pm 6.6$ & $28.7 \pm 6.4$ & --- & $18.0 \pm 7.3^{* * * * *}$ \\
\hline Quadrant2 - Distal & $7.9 \pm 6.6$ & $29.8 \pm 7.0$ & $30.9 \pm 3.6$ & $7.5 \pm 5.0$ & $21.7 \pm 3.9^{* * / * * *}$ & -- \\
\hline Quadrant3 - Distal & $29.6 \pm 5.7$ & $6.3 \pm 5.1$ & $28.3 \pm 7.9$ & $5.4 \pm 5.0$ & $19.1 \pm 9.0^{* / *}$ & --- \\
\hline Quadrant4 - Distal & $28.9 \pm 5.4$ & $6.4 \pm 8.8$ & $6.8 \pm 5.4$ & $28.8 \pm 8.9$ & --- & $18.7 \pm 8.5^{* * / *}$ \\
\hline
\end{tabular}

were not submitted to RSD was: $r=0.9809 ; 95 \%$ confidence interval (CI): $0.9445-0.9935 ; \mathrm{P}<0.0001$ for the left renal artery (LRA), and $\mathrm{r}=0.9825$; $95 \% \mathrm{CI}$ : $0.9489-0.9941$; $\mathrm{P}<0.0001$ for the right renal artery (RRA). To the subjects that underwent RSD, the same correlation, before the procedure, was: $r=0.9726$; $95 \%$ CI: $0.9209-0.9907 ; \mathrm{P}<0.0001$ for the LRA, and $\mathrm{r}=0.9925$; $95 \% \mathrm{CI}$ : $0.9780-0.9455$; $\mathrm{P}<0.0001$ for the RRA. And after the RSD, this correlation was: $r=0.8165$; $95 \%$ CI: 0.5388 - 0.9341; $\mathrm{P}=0.0001$ for the LRA, and $\mathrm{r}=0.9364$; $95 \%$ CI: $0.8225-0.9781$; $\mathrm{P}<0.0001$ for the RRA. According to Tables 2 and 3 respectively, we can observe which areas are most susceptible to VT occurrence during RNS, and the changes of the invasive systolic BP in this population. The 20 CKD subjects on stage 4 which were not submitted to RSD presented area under the roc curve (AUC) $=0.9993 / 0.9985,95 \%$ confidence interval $(\mathrm{CI})=0.9965$ to $0.9997 / 0.9958$ to $0.9994, \mathrm{P}$ value $<0.0001 /<0.0001$, sensitivity $=95 \% / 98 \%$, specificity $=99 \% / 100 \%$, and the cutoff point of $\Delta$ invasive systolic blood pressure to trigger VT during RNS $>25.5 \mathrm{mmHg} />25.5 \mathrm{mmHg}$, from the LRA and RRA, respectively. The other $20 \mathrm{CKD}$ subjects on stage 4 that underwent RSD subsequently showed before the procedure the AUC $=0.9980 / 0.9990$, $95 \% \mathrm{CI}=0.9956$ to $0.9993 / 0.9986$ to 0.9995 , $\mathrm{P}$ value $<0.0001 /<0.0001$, sensitivity $=96 \% / 99 \%$, specificity $=100 \% / 100 \%$, and the cutoff point of $\Delta$ invasive systolic blood pressure to trigger VT during RNS $>25.5$ $\mathrm{mmHg} />24.5 \mathrm{mmHg}$, from the LRA and RRA, respectively. After the $\mathrm{RSD}$, the $\mathrm{AUC}=1.0000,95 \% \mathrm{CI}=1.0000$ to 1.0000 , $\mathrm{P}$ value $<0.0001$, sensitivity $=100 \%$, specificity $=100 \%$, and the cutoff point of $\Delta$ invasive systolic blood pressure to trigger VT during RNS $>25.5 \mathrm{mmHg}$, for both arteries.

In our study, after RSD a decline occurred in the incidence of ventricular arrhythmias and blood pressure rise provoked by RNS, even during new acute subsequently RNS in patients with CKD on stage 4. Our results suggest that RSD can control the higher incidence of malignant arrhythmias in advanced CKD stages.

\section{Conflict of interests}

The authors declare no conflict of interest.

\section{Funding}

This study was funded by Pacemed (U\$ 500,000).

\section{Acknowledgements}

The authors thank all participants of this study and Pacemed by technical support. The study was sponsored by health plans in the state of Rio de Janeiro and the Pacemed.

\section{References}

1. Roger VL, Go AS, Lloyd-Jones DM, Benjamin EJ, Berry JD, et al. (2012) Heart disease and stroke statistics--2012 update: a report from the American Heart Association. Circulation 125: e2-2e220. [Crossref]

2. Myerburg RJ, Junttila MJ (2012) Sudden cardiac death caused by coronary heart disease. Circulation 125: 1043-1052. [Crossref]

3. Departamento de Estimulação Cardíaca Artificial da Sociedade Brasileira de Cirurgia Cardiovascular (DECA/SBCCV). Diretrizes Brasileiras de Dispositivos Cardíacos Eletrônicos Implantáveis do Departamento de Estimulação Cardíaca Artificial (DECA) da Sociedade Brasileira de Cirurgia Cardiovascular (SBCCV) (2015) 5 de agosto de $1-62$.

4. Moss AJ, Hall WJ, Cannom DS, Daubert JP, Higgins SL, et al. (2016) Improved survival with an implanted defibrillator in patients with coronary disease at high risk for ventricular arrhythmia. Multicenter Automatic Defibrillator Implantation Trial Investigators. $N$ Engl J Med 335: 1933-40.

5. Moss AJ, Zareba W, Hall WJ, Klein H, Wilber DJ, et al. (2002) Prophylactic implantation of a defibrillator in patients with myocardial infarction and reduced ejection fraction. $N$ Engl J Med 346: 877-883. [Crossref]

6. Goldstein S, Landis JR, Leighton R, Ritter G, Vasu CM, et al. (1985) Predictive survival models for resuscitated victims of out-of-hospital cardiac arrest with coronary heart disease. Circulation 71: 873-880. [Crossref]

7. Grassi G (2010) Sympathetic neural activity in hypertension and related diseases. Am J Hypertens 23: 1052-1060. [Crossref]

8. Grassi G (2009) Assessment of sympathetic cardiovascular drive in human hypertension: achievements and perspectives. Hypertension 54: 690-697. [Crossref]

9. Paton JF, Raizada MK (2010) Neurogenic hypertension. Exp Physiol 95: 569-571 [Crossref]

10. Tinucci T, Abrahão SB, Santello JL, Mion D Jr (2001) Mild chronic renal insufficiency induces sympathetic overactivity. J Hum Hypertens 15: 401-406. [Crossref]

11. Schlaich MP, Socratous F, Hennebry S, Eikelis N, Lambert EA, et al. (2009) Sympathetic activation in chronic renal failure. J Am Soc Nephrol 20: 933-939. [Crossref]

12. Neumann J, Ligtenberg G, Klein, II, Koomans HA, Blankestijn PJ (2004) Sympathetic hyperactivity in chronic kidney disease: pathogenesis, clinical relevance, and treatment. Kidney Int 65: 1568-76.

13. Grassi G, Bertoli S, Seravalle G (2012) Sympathetic nervous system: role in 
hypertension and in chronic kidney disease. Curr Opin Nephrol Hypertens 21: 46-51. [Crossref]

14. Go AS, Chertow GM, Fan D, McCulloch CE, Hsu CY (2004) Chronic kidney disease and the risks of death, cardiovascular events, and hospitalization. $N$ Engl J Med 351: 1296-1305. [Crossref]

15. Kiuchi MG, Chen S, Pürerfellner H (2016) Incidence of ventricular arrhythmic events in CKD patients with ICD. Int J Cardiol [Epub ahead of print]

16. Martinelli Filho M, Zimerman LI, Lorga AM, Vasconcelos JTM, Rassi A Jr, et al. (2007) Guidelines for Implantable Electronic Cardiac Devices of the Brazilian Society of Cardiology. Arq Bras Cardiol 89: e210-e238.

17. Levey AS, Stevens LA, Schmid CH, Zhang YL, Castro AF 3rd, et al. (2009) A new equation to estimate glomerular filtration rate. Ann Intern Med 150: 604-612. [Crossref]

18. Kiuchi MG, Chen S (2016) Renal sympathetic stimulation in patients with controlled hypertension and paroxysmal atrial fibrillation. Int J Cardiol 224: 394-397.

19. Kiuchi MG, Mion D Jr, Graciano ML, de Queiroz Carreira MA, Kiuchi T, et al. (2016) Proof of concept study: Improvement of echocardiographic parameters after renal sympathetic denervation in CKD refractory hypertensive patients. Int J Cardiol 207: $6-12$.

Copyright: (C2017 Kiuchi MG. This is an open-access article distributed under the terms of the Creative Commons Attribution License, which permits unrestricted use, distribution, and reproduction in any medium, provided the original author and source are credited. 